\section{Ethidium Bromide-induced Mutations from Inflorescence Cultures of Indiangrass}

\author{
Loren C. Stephens ${ }^{1}$ \\ Department of Horticulture, Iowa State University, 106 Horticulture Hall, \\ Ames, IA 50011
}

Additional index words. mutation breeding, ornamental plant breeding, Sorghastrum nutans

\begin{abstract}
Immature inflorescences of a Sorghastrum nutans (L.) Nash selection were cultured on $\mathrm{CCm}$ medium with $5 \mathrm{mg} \cdot \mathrm{L}^{-1} 2,4$-dichlorophenoxyacetic acid and $1 \mathrm{mg} \cdot \mathrm{L}^{-1} \mathrm{~N}^{6}$ benzyladenine (BA) for 5 weeks. Callused inflorescence cultures were placed on $\mathrm{CCm}$ medium with $1 \mathrm{mg} \cdot \mathrm{L}^{-1} \mathrm{BA}\left(\mathrm{CCmB}^{1}\right)$ and 0 or $250 \mathrm{mg} \cdot \mathrm{L}^{-1}$ ethidium bromide (EtBr) for $24 \mathrm{~h}$. Cultures were transferred to $\mathrm{CCmB}^{1}$ without EtBr for shoot regeneration and then to $\mathrm{CCm}$ without plant growth regulators for rooting. Rooted shoots were transferred to soil under greenhouse conditions and then to the field. Fifteen putative $M_{1}$ mutants with atypical phenotypes were detected among 71 EtBr-treated regenerants. Two selfincompatible putative $M_{1}$ mutants were progeny-tested by using a wild-type Indiangrass seedling as the pollen parent. $M_{1}$ selection ISU06-35 was a dwarf mutant whose $M_{2}$ testcross progeny segregated 1:1 tall:dwarf seedlings. $M_{1}$ selection ISU06-56 was a redflowered mutant whose $M_{2}$ testcross progeny segregated 1:1 green-flowered:redflowered seedlings. These results are consistent with both $M_{1}$ mutants being dominant nuclear mutations.
\end{abstract}

Recent years have seen an upsurge in the use of ornamental grasses in commercial and residential landscaping (Engebretson, 2006). Native North American grasses have become especially popular because of their natural hardiness, tolerance for widely different soil types, and drought tolerance (Darke, 1999). Of the native grasses, Indiangrass [Sorghastrum nutans (L.) Nash] is arguably the most widely adaptable with a range that encompasses over half the continental United States. Additionally, it was the second most common grass species in the original tallgrass prairie (Darke, 1999). It is surprising then that so few ornamental cultivars are available. Not counting those adapted from forage types and unnamed selections, only 'Sioux Blue' and the more recently introduced 'Indian Steel' are commonly available from commercial catalog and online nurseries. One possible reason for this lack of cultivars is the presence of self-incompatibility (McKone et al., 1998), which complicates conventional breeding methods, making it more difficult to introduce improvements by combining one

\footnotetext{
Received for publication 8 Jan. 2009. Accepted for publication 6 Apr. 2009.

Journal paper of the Iowa Agriculture and Home Economics Experiment Station, Ames, IA, and supported by the Hatch Act and State of Iowa funds. Financial support from the C.E. Watts Foundation is greatly appreciated.

I thank Henry G. Taber for plot space and technical support; the Iowa State University Turfgrass Program for plant material; and Mark Widrlechner, Shui-zhang Fei, and two anonymous reviewers for useful improvements to the manuscript.

${ }^{1}$ To whom reprint requests should be addressed; e-mail 1cs@iastate.edu.
}

or two useful traits into an already acceptable selection or cultivar.

Mutagenesis has been successfully used in plant breeding for decades, especially when barriers exist to conventional breeding methods (Donini and Sonnino, 1998). Although in vitro culture alone has produced many spontaneous mutations or somaclonal variants (Veilleux and Johnson, 1998), the use of chemical mutagens combined with in vitro culture has been a successful alternative approach for plants not prone to somaclonal variation (Ahloowalia, 1998). One such mutagen, ethidium bromide (EtBr), has been used successfully as a seed soak (Burton and Hanna, 1976), but there are no reports of it being used in vitro.

The primary objective of this study was to determine if EtBr included in the tissue culture medium would induce new phenotypes in Indiangrass. A secondary objective was to select and test mutations of horticultural value for genetic transmission to progeny.

\section{Materials and Methods}

The original plant, hereafter the $\mathrm{M}_{0}$ plant, following previously established terminology (Donini and Sonnino, 1998), was obtained as a transplant of an unnamed selection from Kurt Bluemel Inc. Nurseries, Baldwin, MD, and was established in 2002 at the Iowa State University (ISU) turfgrass plots at the ISU Horticulture Farm, Gilbert, IA. The $\mathrm{M}_{0}$ plant has an upright habit, inflorescences held vertically over the bloom season from September through October, and blue-green summer leaf color similar to other established ornamental Indiangrass cultivars. All plants regenerated from in vitro culture were designated as the $\mathrm{M}_{1}$ generation. Seedlings derived from seeds harvested from the $M_{1}$ selections were designated as the $M_{2}$ generation. The $\mathrm{M}_{0}$ plant was tested in 2005 for its ability to regenerate shoots through in vitro culture following methods established for micropropagation of Indiangrass (Chen et al., 1979) and Miscanthus (Gawel et al., 1990). Of $87 \mathrm{M}_{1}$ regenerants evaluated at the ISU Horticulture Farm, none showed any phenotypic differences from the $\mathrm{M}_{0}$ plant (data not shown), indicating a lack of somaclonal variation. No seeds were set on any $\mathrm{M}_{1}$ plants, suggesting that the $\mathrm{M}_{0}$ plant was selfincompatible. To provide a compatible pollen source for future progeny testing, Indiangrass seeds were harvested in 2005 from the Elwood Prairie, Ames, IA, established using locally sourced seeds from nearby undisturbed prairie remnants (James Colbert, personal communication, 2008).

Shoots were harvested from the $\mathrm{M}_{0}$ plant again in mid-July 2006, when inflorescences were 1 to $5 \mathrm{~cm}$ long within the immature flowering shoot. Following methods of Chen et al. (1979), shoot sections $\approx 9$ to $11 \mathrm{~cm}$ long were disinfected in $75 \%$ commercial liquid bleach $(0.6 \% \mathrm{v} / \mathrm{v}$ sodium hypochlorite $)$, rinsed four times in sterile, deionized water, and plated as longitudinal split-stem sections on CCm semisolid medium (Hodges et al., 1999) with $5 \mathrm{mg} \cdot \mathrm{L}^{-1}$ 2,4-dichlorophenoxyacetic acid $(2,4-\mathrm{D})$ and $1 \mathrm{mg} \cdot \mathrm{L}^{-1}$ benzyladenine (BA; hereafter $\mathrm{CCm} 2{ }^{5} \mathrm{~B}^{1}$ ). After $24-\mathrm{h}$ culture, inflorescences could be separated from the surrounding leaf sheaths and replated onto fresh $\mathrm{CCm} 2^{5} \mathrm{~B}^{1}$ medium. After 5 weeks, all cultures were callused and were transferred to $\mathrm{CCm}$ medium with $1 \mathrm{mg} \cdot \mathrm{L}^{-1}$ BA $\left(\mathrm{CCmB}^{1}\right)$. The $\mathrm{CCmB}^{1}$ medium contained either 0 (control) or $250 \mathrm{mg} \cdot \mathrm{L}^{-1} \mathrm{EtBr}$ by filter-sterilizing $10 \mathrm{~mL}$ of $25 \mathrm{~g} \cdot \mathrm{L}^{-1} \mathrm{EtBr}$ stock solution into $990 \mathrm{~mL}$ warm liquid $\mathrm{CCmB}^{1}$ medium after autoclaving but before pouring into $9-\mathrm{cm}$ petri dishes. After $24 \mathrm{~h}$, cultures from both treatments were transferred to $\mathrm{CCmB}^{1}$ for a 1 -week recovery period after which fresh weight was recorded and then cultures were transferred back to fresh $\mathrm{CCmB}^{1}$ medium. To obtain the culture fresh weight after recovery while minimizing culture stress, weight of the petri dish after transfer of the culture to fresh medium was subtracted from the weight of the petri dish before culture transfer. A $t$ test was performed using Microsoft Office Excel software (Microsoft Corporation, 2007) to test the difference between treatments. After 4 weeks on $\mathrm{CCmB}^{1}$ medium, all callus cultures with visible shoots were transferred to $\mathrm{CCm}$ medium without plant growth regulators. After 4 to 6 weeks, one single-rooted shoot from each shoot clump was placed in a plug cell $\left(2 \mathrm{~cm}^{2}\right)$ in a plug tray and grown until rooting to the bottom of the plug cell, which required another 4 to 6 weeks. Rooted plantlets were overwintered in a cool $10{ }^{\circ} \mathrm{C}$ greenhouse. In mid-March, greenhouse temperature was raised to $20{ }^{\circ} \mathrm{C}$ night temperature. When plants began active shoot growth, they were transplanted to $10-\mathrm{cm}$ diameter 
pots. Cloned and seedling Indiangrass plants were planted at the ISU Horticulture Farm in early May. More than $90 \%$ of plantlets survived transfer to the greenhouse and field survival and flowering of regenerants was $100 \%$. Wild-type Indiangrass seeds were sown in $2-\mathrm{cm}^{2}$ plug cells and germinated under 16-h photoperiods. Germinated seedlings were transplanted to $4.5-\mathrm{cm}$ diameter plug cells, then to $10-\mathrm{cm}$. diameter pots, before being planted in the field. In the greenhouse, seeds were germinated and transplants grown in LC1 medium (Sun Gro Horticulture Ltd., Bellevue, WA), and plants were fertilized as necessary with a balanced soluble fertilizer.

For field planting in 2006, EtBr regenerants were randomized with one control regenerant and one or two wild-type seedlings within each block. The statistical design was a randomized complete block with 12 blocks of eight plants per block. Mature plants were evaluated for three horticultural traits to detect differences from the $\mathrm{M}_{0}$ clone: plant height, flower color, and cytoplasmic male sterility (cms). Cms was evaluated with methods established for pearl millet by Burton and Hanna (1976). To detect dwarf phenotypes, the regenerants from control plates $\left(0 \mathrm{mg} \cdot \mathrm{L}^{-1} \mathrm{EtBr}\right)$ were measured for height at full bloom (soil level to top of tallest inflorescence). The mean and 99\% confidence limits (CLs) were calculated according to methods established by Steel and Torrie (1960). The height of each regenerant from the $\mathrm{EtBr}$ treatment was compared with the mean and CL of the control regenerants. Plants that were taller and shorter (outside the CL) were classified as putative mutants. Seeds were collected from $2 \mathrm{M}_{1}$ selections at the end of the 2006 growing season, ISU06-35

Table 1. Fresh-weight gain of Indiangrass inflorescence callus cultures after removal from $250 \mathrm{mg} \cdot \mathrm{L}^{-1}$ ethidium bromide $(\mathrm{EtBr})$ treatment for $24 \mathrm{~h}$ and placement onto a shoot-inducing medium.

\begin{tabular}{lcc}
\hline Treatments & $\begin{array}{c}\text { Avg wt } \\
\text { gain }(\mathrm{mg})^{\mathrm{z}}\end{array}$ & $\begin{array}{c}\text { Percent } \\
\text { wt gain }^{y}\end{array}$ \\
\hline Control & 267 & $-\overline{47}$ \\
EtBr & 125 & \\
$t$ & $8.85^{* * *}$ & \\
\hline
\end{tabular}

${ }^{\mathrm{z}}$ Weight gain of cultures after 1 week.

${ }^{\mathrm{y}}$ As percent of control.

*** Significant at $P \leq 0.001$.

Table 2. Putative phenotypic $\mathrm{M}_{1}$ mutants among regenerants of Indiangrass observed after ethidium bromide $(\mathrm{EtBr})$ treatment of immature inflorescences.

\begin{tabular}{lcc}
\hline Regenerant & $\begin{array}{c}\text { Number } \\
\text { observed }\end{array}$ & $\begin{array}{c}\text { Percent } \\
\text { putative } \\
\text { mutants }\end{array}$ \\
\hline Dwarf & 14 & 20 \\
Male-sterile & 0 & 0 \\
Colored florets & 1 & 1 \\
\hline
\end{tabular}

${ }^{\mathrm{z}}$ Seventy-one regenerants from EtBr treatment were field-evaluated.

${ }^{y}$ Shorter than the $\mathrm{M}_{0}$ parent-clone mean height of $180 \pm 8 \mathrm{~cm}$ (99\% confidence limit). and ISU06-56, following open-pollination by wild-type Indiangrass seedlings. At the end of the 2006 growing season, $\mathrm{M}_{1}$ selections ISU06-35 and ISU06-56 were dug and transplanted to a site near Slater, IA, 20 miles south of the ISU Horticulture Farm. Each selection was observed over the 2007 season to verify its phenotypic stability. Both $\mathrm{M}_{1}$ selections were divided at the end of the 2007 season to provide clonal propagules for further testing. In 2008, progeny tests were conducted to determine genetic transmission of the two putative mutations. The statistical design was a randomized complete block with each of six blocks containing one plant of $\mathrm{M}_{1}$ selections ISU06-35 and ISU06-56, a wild-type Indiangrass seedling, an ISU06-35 × wild-type Indiangrass $\mathrm{M}_{2}$ seedling, and an ISU06-56 $\times$ wild-type Indiangrass $\mathrm{M}_{2}$ seedling. The mean and 95\% CL (Steel and Torrie, 1960) were calculated separately for the wild-type Indiangrass seedlings and for the $\mathrm{M}_{1}$ selection ISU06-35. Each ISU06-35 $\times$ wild-type $\mathrm{M}_{2}$ seedling was classified as tall or dwarf based on its height being within the 95\% CL for the wild-type seedling mean or the $95 \% \mathrm{CL}$ for the dwarf $\mathrm{M}_{1}$ selection ISU06-35 mean. $\chi^{2}$ goodness-of-fit statistical analyses were performed with methods described by Steel and Torrie (1960).

\section{Results and Discussion}

The average fresh weight gain of EtBrtreated inflorescence-derived callus after 1 week on $\mathrm{CCm} 2{ }^{5} \mathrm{~B}^{1}$ medium was approximately half of the weight gained by the control callus not subjected to EtBr treatment (Table 1) $(P \leq 0.001)$. Burton and Hanna (1976) had previously established $250 \mathrm{mg} \cdot \mathrm{L}^{-1}$ and $1000 \mathrm{mg} \cdot \mathrm{L}^{-1}$ as being effective $\mathrm{EtBr}$ concentrations based on $\mathrm{LD}_{50}$ (lethal dose at which $50 \%$ were killed) dosage trials of seeds soaked for $40 \mathrm{~h}$ at $5{ }^{\circ} \mathrm{C}$. Although $1000 \mathrm{mg} \cdot \mathrm{L}^{-1}$ resulted in more mutants in their study, a dosage of $250 \mathrm{mg} \cdot \mathrm{L}^{-1}$ for $24 \mathrm{~h}$ was used in this study with the expectation that there would be more complete penetration of the chemical into tissue cultures compared with seeds that included a seedcoat as a penetration barrier. Preliminary trials showed that exposure to $250 \mathrm{mg} \cdot \mathrm{L}^{-1}$ for $48 \mathrm{~h}$ resulted in a much greater incidence of later tissue death (data not shown). A $50 \%$ reduction in weight gain of the EtBr-treated callus (Table 1) was judged to be roughly analogous to an $\mathrm{LD}_{50}$ dosage and therefore $250 \mathrm{mg} \cdot \mathrm{L}^{-1} \mathrm{EtBr}$ for $24 \mathrm{~h}$ is the proposed equivalent $\mathrm{LD}_{50}$ dosage for Indiangrass tissue cultures. Although all chemical mutagens are hazardous chemicals, $\mathrm{EtBr}$ is so widely used as an intercalating dye for DNA studies (Maniatis et al., 1982) that safe handling and disposal practices are well established (Anonymous, 2008).

Fifteen putative phenotypic mutants were detected among $71 \mathrm{EtBr}$-treated $\mathrm{M}_{1}$ regenerants in the 2006 field study (Table 2). Most were dwarf plants. Of the height mutants, 14 were shorter than the parent $\mathrm{M}_{0}$ clone height, whereas one was slightly but statistically taller. Twenty-one percent of the EtBr-treated regenerants were classified as putative phenotypic mutants. No chlorophyll-deficient or $\mathrm{cms}$ mutants were detected in contrast to previous work with pearl millet (Burton and Hanna, 1976).

Two putative mutants were selected at the end of the 2006 growing season for genetic testing and for potential horticultural value. $\mathrm{M}_{1}$ selection ISU06-35 has a dwarf phenotype, which is noticeably shorter than $\mathrm{M}_{1}$ selection ISU06-56 (Fig. 1), the same height

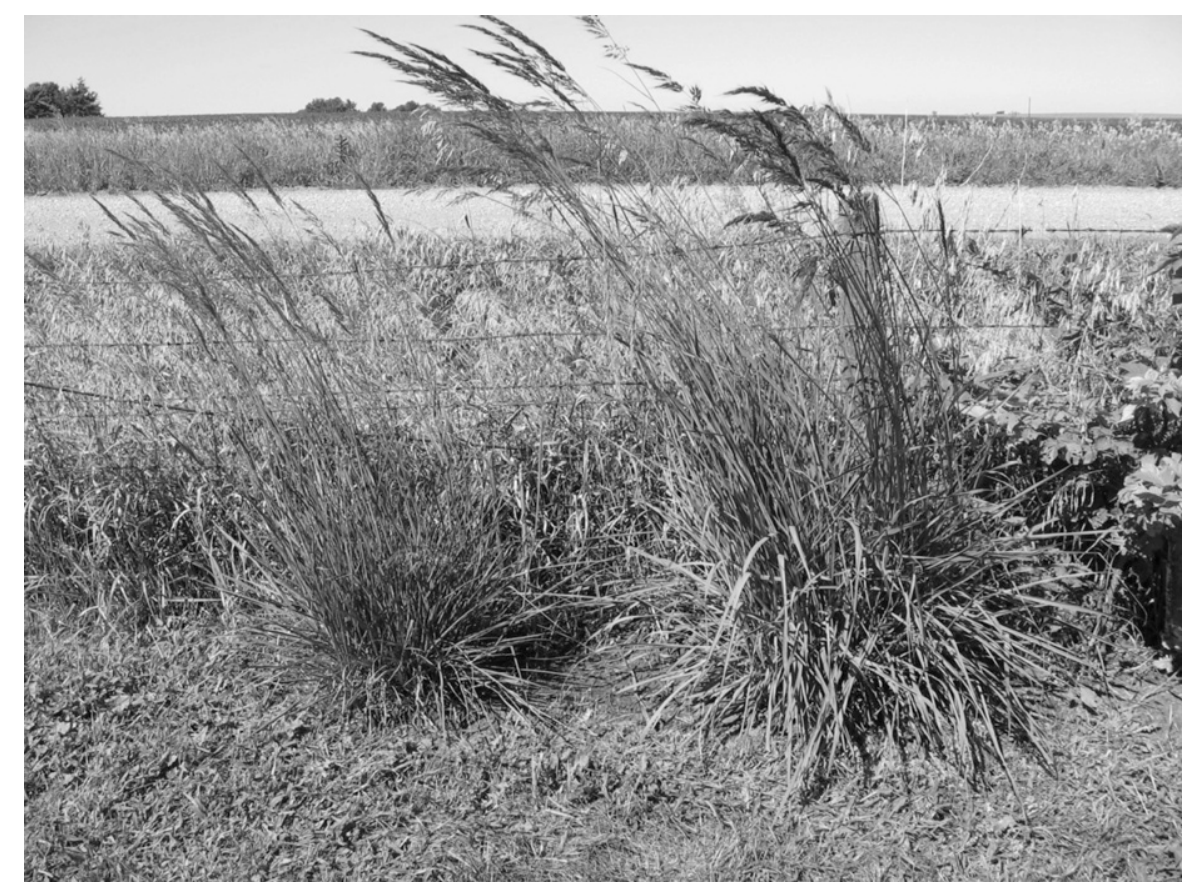

Fig. 1. Dwarf Indiangrass $M_{1}$ selection ISU06-35 (left) compared with red-flowered $M_{1}$ selection ISU0656 (right). Height of selection ISU06-56 is similar to that of the $\mathrm{M}_{0}$ clonal parent. 
statistically as the original $\mathrm{M}_{0}$ plant (data not shown). The dwarf phenotype of ISU06-35 was stable in the 2007 and 2008 growing seasons. ISU06-35 has narrower stiff leaves that remain upright throughout the growing season. ISU06-56 has florets with reddish purple hairs on the palea and lemma enclosing the sessile floret (Fig. 2). Indiangrass has a second vestigial floret (McKone et al., 1998), of which the pedicel can be seen extending along the upper side of the sessile floret. This second floret also has reddish purple hairs on the surface of its pedicel. By contrast, the florets of the wild-type Indiangrass flower have hairs that are nearly transparent, allowing the green of the palea and lemma to be the most prominent color with pink tinting on some of the hairs. Based on the Royal Horticultural Society's color chart (Royal Horticultural Society, 1966), the hairs on the pedicel of the vestigial floret and on the palea and lemma of the sessile floret of ISU06-56 give an overall color impression of grayed purple $183 \mathrm{~B}-\mathrm{C}$ with a grayed green 195B undertone. The wild-type flower color presents an overall color impression of

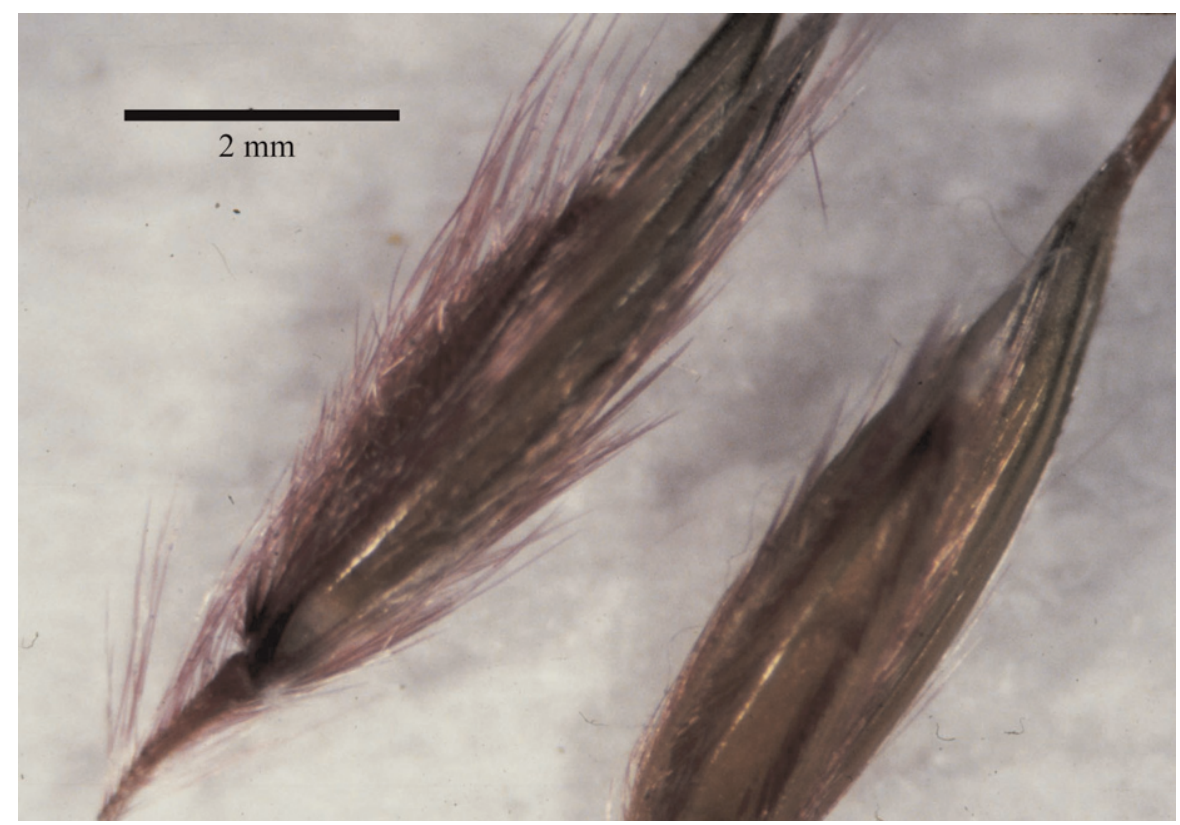

Fig. 2. Indiangrass $M_{1}$ selection ISU06-56 florets $10 \mathrm{~d}$ postanthesis (upper left) compared with $\mathrm{M}_{0}$ clonalparent florets (lower right). Reddish purple hairs of ISU06-56 on vestigial-floret pedicel and on palea and lemma of sessile floret contrast with predominantly transparent hairs of the $\mathrm{M}_{0}$ clonal-parent florets (to view this image in color, see HortScience online at: http://hortsci.ashspublications.org).

Table 3. $\chi^{2}$ analysis of the number of tall (wild-type):dwarf (mutant) $M_{2}$ seedlings from $M_{1}$ selection ISU06-35 $\times$ wild-type Indiangrass.

\begin{tabular}{lccc}
\hline Seedling classification & \\
\hline Tall & Genotypes & Observed & Expected $^{\mathrm{y}}(1: 1)$ \\
Dwarf & $+/+$ & 4 & 3 \\
Total & Dwfl+ & 2 & 3 \\
& $\chi^{2}$ (goodness-of-fit) $=0.66$ NS & 6 & \\
\hline
\end{tabular}

${ }^{2}$ Classified as tall seedlings based on the height being within the $95 \%$ confidence limit (CL) for the wildtype seedling mean $(155 \pm 35 \mathrm{~cm})$ and as dwarf seedlings based on the height being within the $95 \% \mathrm{CL}$ for the dwarf clonal selection ISU06-35 mean $(99 \pm 26 \mathrm{~cm})$.

${ }^{\mathrm{y}}$ Based on a 1:1 ratio of tall:dwarf seedlings, assuming the dwarf (ISU06-35) $\mathrm{M}_{1}$ seed parent is heterozygous. $D w f l+$ for the dominant $D w f$ allele, self-incompatible, and all $\mathrm{M}_{2}$ offspring are descended from a tall, wild-type pollen parent.

NS $=$ nonsignificant.

Table 4. $\chi^{2}$ analysis of the number of green-flowered (wild-type):red-flowered (mutant) $\mathrm{M}_{2}$ seedlings from $\mathrm{M}_{1}$ selection ISU06-56 $\times$ wild-type Indiangrass.

\begin{tabular}{lccc}
\hline Seedling classification & & Observed & Expected $^{\mathrm{y}}(1: 1)$ \\
\hline Green-flowered & Genotypes & 1 & 3 \\
Red-flowered & $+/+$ & 5 & 3 \\
Total & Red $/+$ & 6 & \\
& $\chi^{2}$ (goodness-of-fit) $=2.66$ NS
\end{tabular}

${ }^{{ }^{2}}$ Classified as green-flowered or red-flowered based on visual examination with a $5 \times$ field lens (see Fig. 2) ${ }^{\mathrm{y}}$ Based on a 1:1 ratio of green-flowered/red-flowered seedlings, assuming the red-flowered (ISU06-56) $\mathrm{M}_{1}$ seed parent is heterozygous. Redl+ for the dominant Red allele, self-incompatible, and all $\mathrm{M}_{2}$ offspring are descended from a green-flowered, wild-type pollen parent.

$\mathrm{NS}=$ nonsignificant. grayed green 195B with a grayed purple $183 \mathrm{C}$ undertone. None of the putative or genetically tested mutants were obviously chimeric, suggesting that mutants arose early during shoot organogenesis or arose in cells that subsequently formed somatic embryos.

The ISU06-35 $\mathrm{M}_{1}$ selection, used as a seed parent and crossed with a wild-type Indiangrass seedling pollen parent, produced $6 \mathrm{M}_{2}$ seedling offspring (Table 3 ). The height of each $\mathrm{M}_{2}$ offspring was measured and classified as dwarf (mutant) or tall (normal or wild-type). Dwarf $\mathrm{M}_{2}$ seedlings were all within the 95\% CL for the dwarf ISU06-35 $\mathrm{M}_{1}$ selection mean height of $99 \mathrm{~cm}$. Tall $\mathrm{M}_{2}$ seedlings were all within the $95 \%$ CL for the wild-type seedling mean height of $155 \mathrm{~cm}$. The ratio of tall:dwarf seedlings fit a 1:1 ratio (Table 3), which would be expected if the dwarf allele in ISU06-35 was a dominant nuclear mutation and ISU06-35 was selfincompatible but crosscompatible with the wild-type Indiangrass pollen parent. All $\mathrm{M}_{2}$ seedling offspring of the ISU06-35 $\times$ wildtype cross had a leaf width of $1.3 \mathrm{~cm}$, the same as the wild-type pollen parent, in contrast to ISU06-35, which had a leaf width of $1.0 \mathrm{~cm}$. This result suggests that all $\mathrm{M}_{2}$ offspring were the result of a crosspollination rather than from self-pollination of ISU0635 , confirming the self-incompatible nature of the original $\mathrm{M}_{0}$ parent clone and its derived $\mathrm{M}_{1}$ selections, ISU06-35 and ISU06-56.

The ISU06-56 $\mathrm{M}_{1}$ selection, used as a seed parent and crossed with a wild-type Indiangrass seedling pollen parent, produced $6 \mathrm{M}_{2}$ seedling offspring (Table 4). The floret color of each $\mathrm{M}_{2}$ offspring was determined $10 \mathrm{~d}$ after anthesis. The ratio of green-flowered:red-flowered seedlings fit a 1:1 ratio (Table 4), which would be expected if the red-flowered allele in ISU06-56 was a dominant nuclear mutation and ISU06-56 was self-incompatible but crosscompatible with the wild-type Indiangrass pollen parent.

This study shows that Indiangrass, like Miscanthus (Gawel et al., 1990), is stable genetically by micropropagation and that $\mathrm{EtBr}$ can be used in the tissue culture medium to generate genetic mutations. The mutation rate was at least $3 \%$ and less than or equal to $23 \%$ (Table 2) based on sampling three phenotypic mutant classes. Whereas Burton and Hanna (1976) reported one male-sterile mutant per 515 inflorescences and four chlorophyll-deficient mutants in $402 \mathrm{M}_{2}$ progenies of pearl millet, it is difficult to compare directly the rate of mutation in the two studies, because of differences in the way each study was conducted, e.g., seed versus tissue treatments, and the type of genetic mutants that occurred, i.e., cytoplasmic versus nuclear. $\mathrm{Nev}$ ertheless, EtBr is an effective mutagen in both tissue cultures and as a seed-based treatment.

\section{Literature Cited}

Ahloowalia, B.S. 1998. In-vitro techniques and mutagenesis for the improvement of vegetatively propagated plants, p. 293-309 In: Jain, S.M., D.S. Brar, and B.S. Ahloowalia (eds.). Somaclonal variation and induced mutations in 
crop improvement. Kluwer Acad. Publ., Dordrecht, The Netherlands.

Anonymous. 2008. Ethidium bromide fact sheet. Environmental Health and Safety, Iowa State University, Ames, IA. 4 Nov. 2008. <http:// www.ehs.iastate.edu/publications/factsheets/ ethidiumbromide.pdf $>$.

Burton, G.W. and W.W. Hanna. 1976. Ethidium bromide induced cytoplasmic male sterility in pearl millet. Crop Sci. 16:731-732.

Chen, C.H., P.F. Lo, and J.G. Ross. 1979. Regeneration of plantlets from callus cultures of Indiangrass (Sorghastrum nutans). Crop Sci. 19:117-118.

Darke, R. 1999. The color encyclopedia of ornamental grasses. Timber Press, Portland, OR.

Donini, P. and A. Sonnino. 1998. Induced mutations in plant breeding: Current status and future outlook, p. 255-291 In: Jain, S.M.,
D.S. Brar, and B.S. Ahloowalia (eds.). Somaclonal variation and induced mutations in crop improvement. Kluwer Acad. Publ., Dordrecht, The Netherlands.

Engebretson, D. 2006. Glorious grasses. Northern Grower 134:16.

Gawel, N.J., C.D. Robacker, and W.L. Corely. 1990. In vitro propagation of Miscanthus sinensis. HortScience 25:1291-1293.

Hodges, C.F., L.C. Stephens, and D.A. Campbell. 1999. Ethylene and ethane from Poa pratensis callus and from leaf blades of regenerated and seed-derived plants inoculated with Bipolaris sorokiniana. J. Plant Physiol. 154:113118.

Maniatis, T., E.F. Fritsch, and J.J. Sambrook. 1982. Molecular cloning: A laboratory manual. Cold Spring Harbor Laboratory, Cold Spring Harbor, NY.
McKone, M.J., C.P. Lund, and J.M. O'Brien. 1998. Reproductive biology of two dominant prairie grasses (Andropogon gerardii and Sorghastrum nutans, Poaceae): Male-biased sex allocation in wind-pollinated plants? Amer. J. Bot. 85:776-783.

Microsoft Corporation. 2007. Microsoft Office Excel, Version 2007. Microsoft Corp., Redmond, WA.

Royal Horticultural Society. 1966. The Royal Horticultural Society colour chart. London, UK.

Steel, R.G.D. and J.H. Torrie. 1960. Principles and procedures of statistics. McGraw-Hill Inc., New York, NY.

Veilleux, R.E. and A.A.T. Johnson. 1998. Somaclonal variation: Molecular analysis, transformation interaction, and utilization. Plant Breed. Rev. 16:229-268. 